\title{
APPLICATION OF ANALYTIC HIERARCHY PROCESS FOR STRATEGIC PLANNING AND IMPLEMENTATION AT NEPALESE UNIVERSITIES AND COLLEGES
}

\author{
Prabal Sapkota \\ School of Engineering \\ Kathmandu University \\ Dhulikhel, Kavre, Nepal \\ E-mail:prabal@ku.edu.np
}

\begin{abstract}
Due to the increasing competition in higher education, time has come for the Nepalese educational institutions to identify their core competencies. Even though strategic planning is practiced by some of the institutions, management is often lost during the implementation of the strategic plan. Several goals, objectives and strategic paths have been found to be identified during the strategic planning. Due to unavailability of enough resources, all the goals and objectives cannot be achieved together. This research has been done to assist the management in prioritizing the most important goal, objective and strategic path for the educational institute to achieve its vision. The work has been conducted in two different types of educational institutions with different vision and different sets of problem they were facing. The research could provide guidelines for universities and colleges of developing countries with constraints in resources and time to achieve the desired vision.
\end{abstract}

Key words: Nepalese educational institutions, strategic planning, goals, objectives, AHP

\section{Introduction}

The world is getting competitive and no sector can stay away from competition. In recent times, the competition has tremendously grown in the education sector as well. Most universities and colleges are trying to concentrate in achieving competitive advantage. What works for one university may not work for another. Rather, each university should have its own strategy. Strategic planning is a roadmap to lead a university from where it is now to where it would like to be in the future. It should be flexible, practical and serve as a guide to implement programs, to make continuous evaluation and necessary adjustments. Strategic planning and decision making is not an easy process. There is no hard and fast rule regarding which objective or goal should be considered. During the process several factors, sub factors and criteria come into play. Strategic planning process is the true case of multi criteria decision making (MCDM) where several conflicting aspects need to be addressed. Among several MCDM tools available, Analytic Hierarchy Process (AHP) has been used for this research.

It has been found that only a few Nepalese institutions follow strategic planning process, but the process has not been structured properly with clear vision, mission, goals and objectives. This study focuses on the strategic planning and implementation at two Nepalese educational institutions. The first one is well established and considered best among different institutes in the country, offering both undergraduate and graduate level courses in several disciplines. The second one is a newly established college offering undergraduate study in engineering. 
Sapkota P. / Application of Analytic Hierarchy Process for Strategic Planning and Implementation at Nepalese Universities and Colleges

\subsection{Rationality of the study}

The competition in higher education in Nepal is very high. Nepalese universities and colleges have to compete both with national and international universities. Every year several thousands of Nepalese students go to foreign universities for higher education. Due to that, most of the technical education providing colleges enrolled less than 50\% of their total intake capacities in the years 2012 and 2013. It is evident that some innovation is required in the Nepalese educational sector so as to retain potential Nepalese students within the country. There is a definite need for improvement at the strategic level of these institutes.

\subsection{Problem statement}

\section{Case I: Kathmandu University (KU), Dhulikhel, Kavre, Nepal}

KU is among the best universities of Nepal. Since its establishment in 1991, KU has been engaged in strategic planning process. It has a vision "to become a world-class university devoted to bringing knowledge and technology to the service of mankind". In 2012, a ten year plan of KU (2013 -2022) was approved by the senate meeting. KU wishes to develop a concrete strategic plan which could take it towards its vision of becoming world-class University. Several goals, objectives and long term strategies for KU have already been identified. Although KU does not have difficulties in finding potential students in engineering programs, there is always a challenge of finding intelligent students in other branches of study and qualified faculties. To deal with the current situation and to attain sustainable growth by maintaining its position within the country and expanding in the international arena, it has to identify a particular strategy which could take it towards its vision.

\section{Case II: Hillside College of Engineering (HCE), Koteshwor, Kathmandu, Nepal}

HCE is one of the youngest colleges affiliated to Purbanchal University, Nepal. There is stiff competition among colleges of Purbanchal University as the entrance examination at the time of admission is centrally conducted by the university. Due to this, there is rivalry among the affiliated colleges. Almost all these colleges have similar environments and have nothing new to promote themselves in the competitive market. HCE is always challenged to find both potential students and faculties. Further, it is affiliated to a not so reputed university of the country. To deal with the problem of finding potential students and attain sustainable growth, it has adopted the strategy of research based education. It would be important for HCE to identify the contribution of the different objectives and goals to realize its vision "to become one of the top five research institutes of Nepal”.

In both the above mentioned cases, strategy has been formulated and vision has been set, but the management is confused on how this vision can be achieved. Also, to become one of the best university or college, it needs to have excellence in several fields. Several goals have been set but the management seems to be lost in how to start things, as they are not able to prioritize these goals based on importance to achieving the institute's desired vision. This scenario is an apt example of multi criteria decision making (MCDM). Also, due to the constraints in resources for Nepalese institutes, all the goals and objectives cannot be fulfilled within a short span of time. It is very important to prioritize them based on their importance. This study intends to seek answers to the following research questions:

$>$ What should be the strategic path for KU to take it towards its vision? Which are the most important goals and objectives KU should achieve to pave the path for the identified strategic path?

$>$ Which is the most important goal (and its corresponding objective) for HCE to take it towards its vision? 
Sapkota P. / Application of Analytic Hierarchy Process for Strategic Planning and Implementation at Nepalese Universities and Colleges

\section{Literature review}

The benefit of strategic planning in higher educational institutions is that it can lend stability to the organization in spite of increasingly frequent leadership changes (Paris, 2003). One of the world's influential universities, Cornell University (2009) has identified five central goal areas to achieve university excellence: Faculty; Education; Research, scholarship, and creativity; Outreach and public engagement; Staff and organizational stewardship. Hahn (2002) has highlighted the need of structure to decision making, as it gives the necessary tradeoff between all the alternatives that are being considered. Saaty (2008) highlighted the use of a model that is not overtly complex, legitimately aggregates across scales, and addresses consistency in judgments from multiple participants. AHP is capable of breaking complex problems into smaller parts which can be easily handled by human intelligence (Saaty, 2008). AHP has already been used for academic settings like faculty selection (Grandzol, 2005).

\section{Objectives}

The major objectives of this research are:

$>$ To prioritize goals, corresponding objectives and identify the best strategic path for Kathmandu University to reach its vision.

$>$ To identify the most important goal and corresponding activity for Hillside College of Engineering to be one of the best research institutes of Nepal.

\section{Research design}

The research work has been carried out on AHP. Based on the theory of AHP several steps have been followed which are listed below:

$>$ An AHP model has been developed based on the documents from the strategic plan of KU and HCE, literatures on strategic planning for educational institutions and views from experts.

$>$ Respondent selection for study: Two categories of respondents have been selected for the study at KU. First group includes the people who are directly involved with Kathmandu University: faculties, researchers and project managers. The second groups of people are from the outside of Kathmandu University and are involved in teaching and research. The study at HCE has been done with two groups of people: First group includes members from strategic planning committee (SPC) and the other group is the committee of department heads (CDH).

$>$ A questionnaire based on the pair wise comparison of different levels of hierarchies has been developed.

$>$ Data collection has been done on individual basis with each of the respondents with the proper demonstration of pair wise comparison process and the inconsistency that may result. Individual data has been checked for consistency. Data with inconsistency ratio of less than 0.1 has been accepted.

$>$ The number of valid samples used during the case of KU is 20 ( out of 30 samples only 20 of the samples have inconsistency ratio less than 0.1 ) and that of $\mathrm{HCE}$ is 9 ( $\mathrm{SPC}=5$ and $\mathrm{CDH}=4)$.

$>$ Geometric mean of the valid data collected from individual respondents has been calculated to aggregation. This mean value has been used for further calculation and prioritization of alternatives.

\section{Model Analysis}

A model has been developed based on the vision, objectives, long term strategies and latest ten year plan of KU. The grouping of these objectives with goals has been done 
Sapkota P. / Application of Analytic Hierarchy Process for Strategic Planning and Implementation at Nepalese Universities and Colleges

based on the literatures and consultation with experts. In order to give tangible vision for the purpose of this research, a short term vision has been developed which is "KU to be one of the top Universities of South Asia by 2019". Short term vision of KU is at the level 1 of AHP hierarchy followed by five goals at level 2 and objectives to achieve those goals at level 3 and finally two of the long term strategies of KU have been used as alternatives at level 4. The hierarchy developed is shown in Figure 1.

KU to be one of the top universities of South Asia by 2019

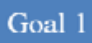

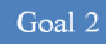

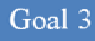

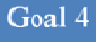

Letel I

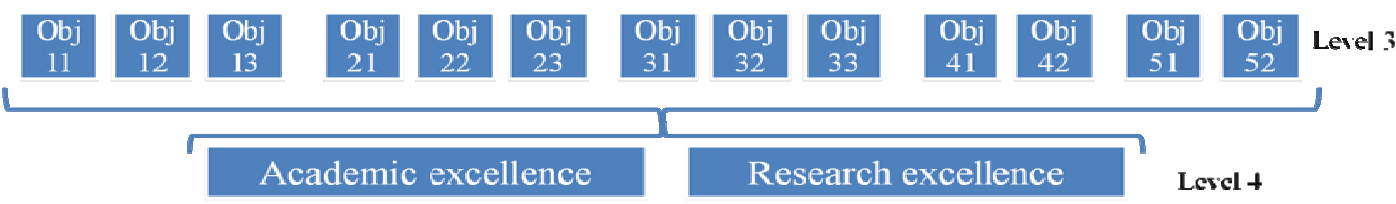

Goal 1: Faculty excellence, Goal 2: Educational excellence, Goal 3: Excellence in organizational culture, Goal 4: Excellence in Research and Scholarship, Goal 5: Excellence in Public engagement, Obj: Objective

Figure 1 Hierarchy for prioritizing strategic path for Kathmandu University

In case of HCE, a model has been developed with the inclusion of SPC and CDH as separate entities (actors) which could influence the strategic planning process. Vision is at level 1, followed by actors at level 2, goals at level 3 and objectives (activities) to support the goals at level 4. HCE does not have strategic alternatives, and the aim is only to prioritize goals and objectives. The hierarchy for HCE is shown in Figure 2.

\section{$\mathrm{HCE}$ to be one of the top five research institutes of Nepal}

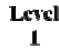

\begin{tabular}{|c|c|c|}
\hline $\mathrm{SPC}$ & Level \\
\hline
\end{tabular}

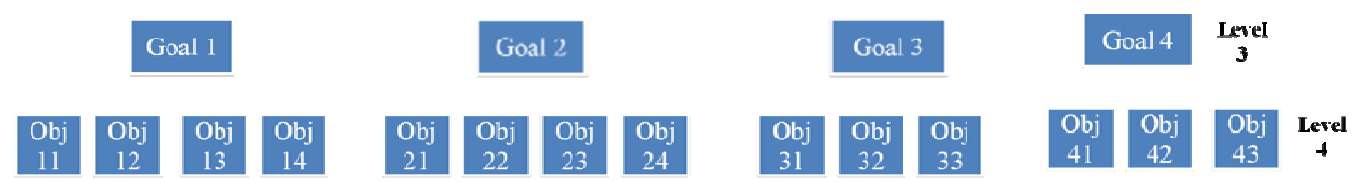

SPC: Strategic Planning Committee, CDH: Committee of Department heads, Goal 1: Faculty excellence, Goal 2: Educational excellence, Goal 3: Excellence in research, scholarship, and creativity, Goal 4: Excellence in Public Engagement; Obj: Objective

Figure 2 Hierarchy for prioritizing goals and objectives for HCE

The response obtained in the form of pair wise comparison has been aggregated by calculating geometric mean using Microsoft Excel 2007. The calculated geometric mean value has been put in matrix form. A sample matrix that has been developed during the calculation is shown in Table 1 . Further calculations have been made in order to calculate priority vector, row average and finally, consistency ratio. The consistency ratio obtained is 0.01 which is lower than the threshold value of 0.1 . Similar matrices have been developed for Objectives with respect to individual goals 
Sapkota P. / Application of Analytic Hierarchy Process for Strategic Planning and Implementation at Nepalese Universities and Colleges

and finally for alternatives with respect to individual objectives. In all the cases, the consistency ratio is less than 0.1 .

Table 1 Pair wise comparison of goals (factors) with respect to vision for KU

\begin{tabular}{llllll} 
Goal 1 & 1 & 1.445 & 1.732 & 0.623 & 2.762 \\
\cline { 2 - 6 } Goal 2 & 0.691 & 1 & 1.651 & 0.598 & 3.527 \\
\cline { 2 - 6 } Goal 3 & 0.577 & 0.605 & 1 & 0.298 & 1.599 \\
\cline { 2 - 6 } Goal 4 & 1.605 & 1.671 & 3.351 & 1 & 3.567 \\
\cline { 2 - 6 } Goal 5 & 0.362 & 0.283 & 0.625 & 0.28 & 1
\end{tabular}

\section{Limitations}

This work has some limitations. There is no unanimity about the best or correct method of aggregating the responses. The method still relies on subjective judgments for the analysis. The weights that are assigned to the decision makers can be tilted in favor such that the result will reflect the opinion of a selected few people. Maintaining consistency is also a very critical factor for the members' views to be accurately reflected in the results. Within a small group, an inconsistent input from a single member can immediately have an effect on the overall rankings. Further, the same model may not be applicable to all the universities and colleges of Nepal. Also the sample size used here is small. It may not be suitable for any other organization which has to deal with various aspects.

\section{Conclusions}

This study is probably the first ever study done at Nepalese university/ college strategic planning from the perspective of MCDM. This research could be an eye opener for Nepalese educational institutions which never believed in strategic planning and identifying competitive advantage. This could be a good model for implementing strategies within the constraints of resources and time. Furthermore, the study has been done on two entirely different levels of institutions, which may cover the entire range of universities and colleges of developing countries like Nepal.

\section{References}

Allison, M. J. (2005). Strategic Planning for Nonprofit Organizations: a Practical Guide and Workbook. N.J 2005: Wiley.

David, F. (2001). Strategic Management: Concepts \& Cases. Upper Saddle River, NJ: Prentice Hall.

Hahn, E. D. (2002). Better Decisions Come from a Results-Based Approach. Marketing News Vol 36, No 19, 24.

Paris, K. A. (2003). Strategic Planning in the University. University of Wisconsin System Board of Regents.

Saaty, T. L. (2008). Decision making with the analytic hierarchy process. Int. J. Services Sciences, Vol. 1, No. 1, P 83-98. 